\title{
The Influence of Climate Conditions and On-Skin Positioning on InGaZnO Thin-Film Transistor Performance
}

\author{
Federica Catania ${ }^{1 *}$, Hugo De Souza Oliveira ${ }^{1}$, Martina A. Costa Angeli ${ }^{1}$, Manuela Ciocca ${ }^{1}$, \\ Salvador Pané ${ }^{2}$, Niko Münzenrieder ${ }^{1}$ and Giuseppe Cantarella ${ }^{1 *}$ \\ ${ }^{1}$ Faculty of Science and Technology, Free University of Bolzano-Bozen, Bolzano, Italy, ${ }^{2}$ Institute of Robotics and Intelligent \\ Systems, ETH Zurich, Zurich, Switzerland
}

\section{OPEN ACCESS}

Edited by:

Aftab M. Hussain,

International Institute of Information

Technology, India

Reviewed by:

Sandeep G. Surya,

Dyson, United Kingdom

Sungsik Lee,

Pusan National University, South

Korea

*Correspondence:

Federica Catania

federica.catania@unibz.it

Giuseppe Cantarella

giuseppe.cantarella@unibz.it

Specialty section:

This article was submitted to

Flexible Electronics,

a section of the journal

Frontiers in Electronics

Received: 30 September 2021 Accepted: 18 November 2021 Published: 06 January 2022

Citation:

Catania F, Oliveira HS,

Costa Angeli MA, Ciocca M, Pané S, Münzenrieder $N$ and Cantarella $G$ (2022) The Influence of Climate Conditions and On-Skin Positioning on InGaZnO Thin-Film

Transistor Performance.

Front. Electron. 2:786601. doi: 10.3389/felec.2021.786601
Thin-film transistors (TFTs) based on amorphous indium-gallium-zinc-oxide (a-IGZO) have proved promising features for flexible and lightweight electronics. To achieve technological maturity for commercial and industrial applications, their stability under extreme environmental conditions is highly required. The combined effects of temperature (T) from $-30.0^{\circ} \mathrm{C}$ to $50.0^{\circ} \mathrm{C}$ and relative humidity $(\mathrm{RH})$ stress from 0 to $95 \%$ on a-IGZO TFT is presented. The TFT performances and the parameters variation were analysed in two different experiments. First, the TFT response was extracted while undergoing the most extreme climate conditions on Earth, ranging from the African Desert $\left(50.0^{\circ} \mathrm{C}, 22 \%\right)$ to Antarctic $\left(-30.0^{\circ} \mathrm{C}, 0 \%\right)$. Afterwards, the device functionality was demonstrated in three parts of the human body (forehand, arm and foot) at low (35\%), medium (60\%) and high (95\%) relative humidity for on-skin and wearable applications. The sensitivity to $\mathrm{T} / \mathrm{RH}$ variations suggests the suitability of these TFTs as sensing element for epidermal electronics and artificial skin.

Keywords: thin-film transistors (TFTs), flexible electronics, oxide semiconductors, indium-gallium-zinc-oxide (IGZO), wearable electronics, humidity sensor, temperature sensor

\section{INTRODUCTION}

The increased interest in flexible and imperceptible electronics has positively impacted on different applications, such as smart textiles Cherenack et al. (2010), epidermal electronics for healthcare Gao et al. (2016), and display technologies Geng et al. (2017). The key element for this rapid evolution is represented by conformable thin-film transistors (TFTs), with stable functionality while a mechanical strain is applied. Among the different TFT technologies, oxide semiconductors, and in particular amorphous Indium-Gallium-Zinc-Oxide (a-IGZO), have proved several advantages to fulfill the requirements for state-of-the-art applications, such as high electrical performance with mobility greater than $10 \mathrm{~cm}^{2} / \mathrm{Vs}$, large-area processability, transparency and low deposition temperatures Yabuta et al. (2006), Nomura et al. (2004), Salvatore et al. (2014). The performances of a-IGZO TFTs fabrication on flexible substrate during tensile and compressive strain are extensively reported Park et al. (2009), Munzenrieder et al. (2011), Hasan et al. (2017), Billah et al. (2017), Münzenrieder et al. (2013). In addition to the mechanical stability, the electrical stability at any environmental condition (light exposure, moisture, temperature (T), relative humidity (RH)) is a key aspect for the employment of a-IGZO TFTs on a large scale Costa et al. (2019). Although different studies concerning the effects of the RH on the IGZO TFT operation have proved a reliable variation for the threshold voltage Knobelspies et al. (2018), Lee and Jeong 

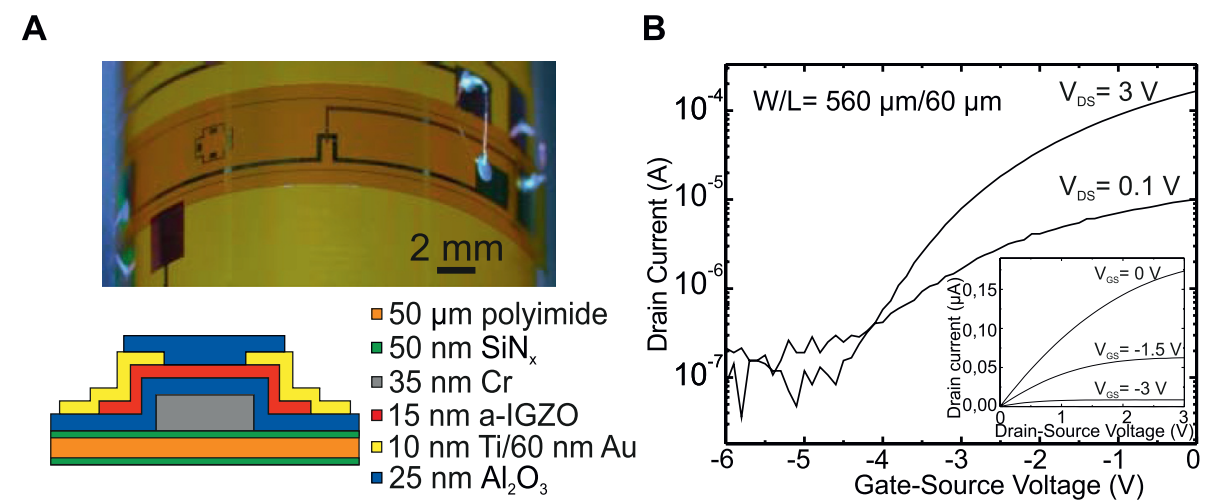

FIGURE 1 | Bottom-gate staggered IGZO TFTs. (A) Optical picture and schematic. The $W / L$ ratio of the transistor is $560 \mu \mathrm{m} / 60 \mu \mathrm{m}$. (B) Transfer characteristic and corresponding output (inset) at room conditions: temperature equals to $23.7^{\circ} \mathrm{C}$ and relative humidity equals to $55 \%$.

(2018), Kim et al. (2017), no common trend in the variations of the other parameters was observed. The dependence of these variations on several parameters, such as light-excitation Zhou et al. (2014), Dong et al. (2019), Knobelspies et al. (2018), traps density Kim et al. (2011) and defects formation Lee and Jeong (2018), Park et al. (2008), fabrication process Hoshino et al. (2013), Corsino et al. (2020), have been investigated. The results were significantly affected by the active layer thickness, as well as the presence/absence of a passivation layer Park et al. (2008), Chowdhury et al. (2015), Dong et al. (2019), Hoshino et al. (2013) while high $\mathrm{T}\left(>150^{\circ} \mathrm{C}\right)$ enables the performance recovery Mativenga et al. (2021), Chowdhury et al. (2015), Hasan et al. (2017). On the other hand, the influence of T variation was shown to improve the drain current leading to a negative threshold voltage shift by increasing T Kim et al. (2011), Godo et al. (2010). Despite the impact of $\mathrm{T}$ and $\mathrm{RH}$ variations on TFTs performance was analysed, all experiments were performed varying one parameter only by keeping the other one constant.

Here, the effects of a simultaneous variation of both temperature and relative humidity were studied. a-IGZO TFTs were first characterized under specific environmental conditions, reproducing the main climate zones of our planet, ranging from Desert $\left(50.0^{\circ} \mathrm{C}, 22 \%\right)$ to Antarctic $\left(-30.0^{\circ} \mathrm{C}, 0 \%\right)$. Additionally, the device response was evaluated by simulating the environmental conditions in proximity of human skin. Here, temperatures associated with three body parts (forehead $35.0^{\circ} \mathrm{C}$, arm $32.0^{\circ} \mathrm{C}$, and foot $29.0^{\circ} \mathrm{C}$ ) were selected and measurements were performed at three RH levels: normal skin humidity (60\%), low humidity (35\%), and ultra-high humidity (95\%) Cravello and Ferri (2008), Choi and Loftness (2012). The results showed the suitability of IGZO TFTs as active electronics and sensor conditioning platform for both wearable and e-skin applications.

\section{TFT FABRICATION AND CHARACTERIZATION}

Figure 1A shows the schematic of the bottom-gate staggered TFT fabricated on a $50-\mu \mathrm{m}$ thick polyimide foil as substrate. The fabrication process and the experiment are described in the following.

\subsection{Fabrication}

The free-standing polyimide foil was cleaned by sonication in acetone and isopropanol for $5 \mathrm{~min}$, respectively, and cured in a vacuum oven at $200^{\circ} \mathrm{C}$ overnight. $50-\mathrm{nm}$ thick $\mathrm{SiN}_{x}$ was deposited through plasma-enhanced chemical vapor deposition (PECVD) on both substrate sides as a buffer layer to ensure good mechanical and chemical stability during the fabrication. Then, the process was started with a 35-nm $\mathrm{Cr}$ metal gate deposited using electron beam evaporation and patterned through standard photolithography. 25-nm thick $\mathrm{Al}_{2} \mathrm{O}_{3}$ gate dielectric was deposited using atomic layer deposition (ALD) and 15-nm thick a-IGZO was sputtered at room temperature to form the active layer. Wet etching was performed to structure the semiconductor island and the vias. 10-nm Ti adhesive layer and 60-nm Au were deposited through electron beam evaporation to form the Source/Drain contacts and patterned by lift-off. Finally, an additional 25-nm thick $\mathrm{Al}_{2} \mathrm{O}_{3}$ was deposited to provide the device passivation. The maximum temperature of the process was $150^{\circ} \mathrm{C}$, reached during the ALD. More details on the fabrication process can be found in Munzenrieder et al. (2011). An optical picture of the finalized device is shown in Figure 1A.

\subsection{Experiment}

The measurements were carried out within an Espec SH-262 climate chamber by setting temperature from $-30.0^{\circ} \mathrm{C}$ to $50.0^{\circ} \mathrm{C}$ and $\mathrm{RH}$ from 0 to $95 \%$. The experiment was conducted in dark to avoid light-induced instability on the IGZO active layer. The flexible TFT was fixed on a rigid glass substrate. The electronics characterization was performed through a Keithley 2614B source meter. The electrical interconnection between the device and the electronics setup was obtained by placing small pieces of $\mathrm{Cu}$ tapes at the edge of the polyimide stripe. Here, short $\mathrm{Cu}$ wires were glued through a silver conductive paste to connect the TFT pads and the tapes. Similarly, long $\mathrm{Cu}$ wires were glued and connected with the source meter. Data were recorded by means of a customized LabVIEW program. 

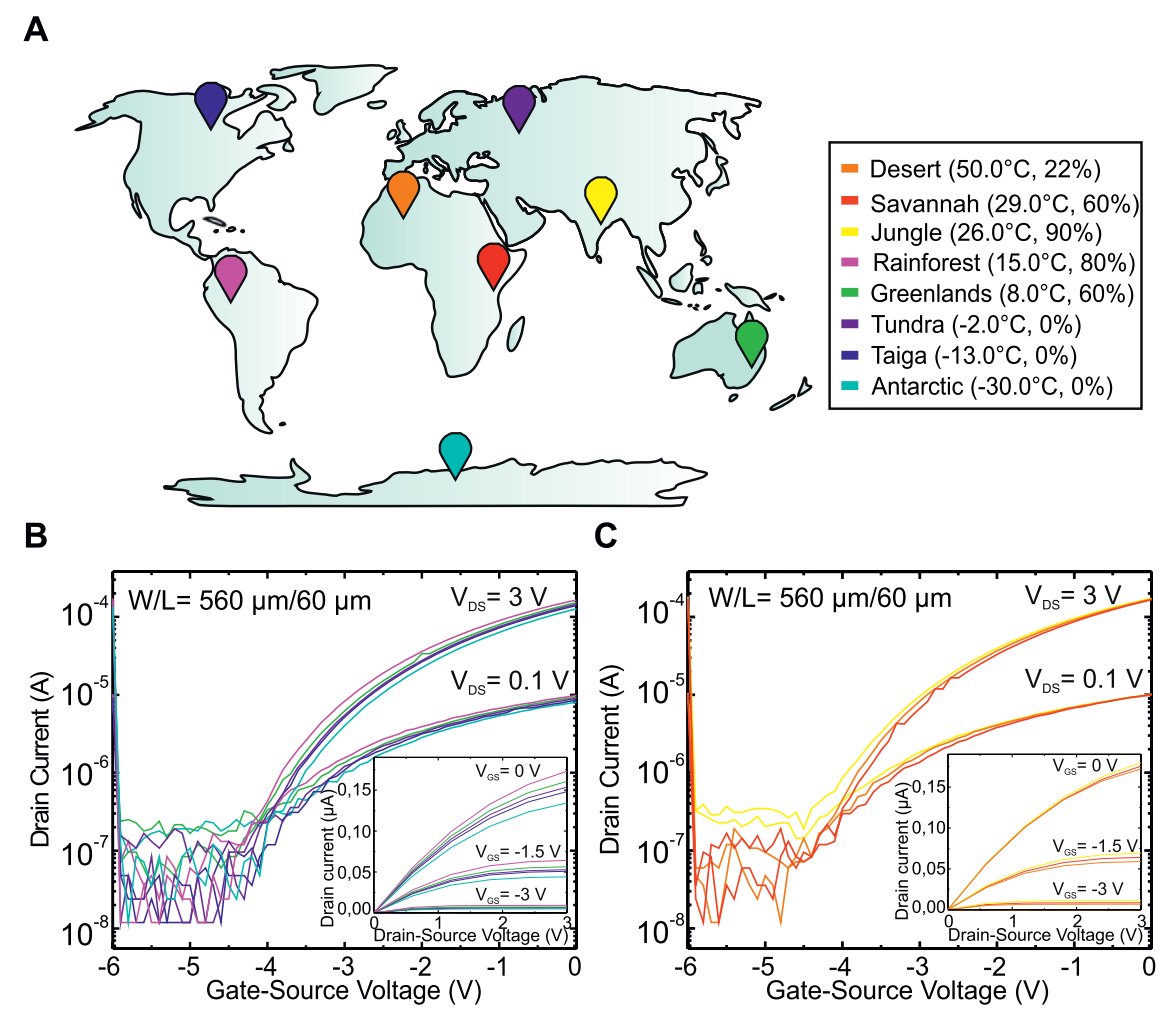

FIGURE 2 | IGZO TFTs performance at different climate zones. (A) Schematic representation of the simulated geographical locations. The legend reports the associated $\mathrm{T}$ and $\mathrm{RH}$ conditions. Transfer characteristics and corresponding output (insets) at temperatures (B) lower and (C) greater than room $\mathrm{T}$.

\subsection{Performance}

The first measurement was performed at room $\mathrm{T}$ and $\mathrm{RH}$ $\left(23.7^{\circ} \mathrm{C}, 55 \%\right)$ to evaluate the TFT performance. Figure 1B shows the TFT transfer characteristic and output. Note that the gate current $\left(\mathrm{I}_{g}\right)$ (not reported here) was in the range of $1 \mu \mathrm{A}$ and the drain current $\left(\mathrm{I}_{d}\right)$ was $0.17 \mathrm{~mA}$ for $\mathrm{V}_{G S}=-6 \mathrm{~V}$. These non-idealities were caused by the employed measurement setup (long $\mathrm{Cu}$ wires and source meter) since a $\mathrm{I}_{g}$ and an $\mathrm{I}_{\text {off }}$ in the order of pico-ampere (pA) were obtained by performing the electronics characterization in a probe station using a parameter analyzer (Agilent Technology B1500A).

The extracted parameters were obtained as follows: threshold voltage $V_{T H}=-3.96 \mathrm{~V}$, subthreshold swing $S S=314 \mathrm{mV} / \mathrm{dec}$, on/off current ratio $I_{\text {on }} / I_{\text {off }}=1.39 \times 10^{4}$, linear field-effect mobility $\mu_{\text {lin }}=8.10 \mathrm{~cm}^{2} / \mathrm{Vs}$. They were evaluated according to standard TFT model equations Sze and $\mathrm{Ng}$ (2006). The negative $\mathrm{V}_{T H}$ defined the TFT functionality in depletion mode.

The mechanical stability of the device was analyzed at room conditions Munzenrieder et al. (2011), Münzenrieder et al. (2013). The influence of both tensile and compressive strain on the electronic parameters was evaluated when the IGZO TFTs were bent to a bending radius of $4 \mathrm{~mm}$ (corresponding to a tensile strain of $0.63 \%$ ) Münzenrieder et al. (2013) and $9 \mathrm{~mm}$ (corresponding to a compressive strain of $0.27 \%$ ) Munzenrieder et al. (2011).
TABLE 1 | TFT electrical performance parameters at different geographical locations.

\begin{tabular}{lcccc}
\hline Clime & $\boldsymbol{V}_{\boldsymbol{T H}} \mathbf{( V )}$ & $\boldsymbol{I}_{\text {on }} \boldsymbol{I}_{\text {off }}$ & SS $(\mathbf{m V / d e c})$ & $\boldsymbol{\mu}_{\boldsymbol{l i n}}\left(\mathbf{c m}^{\mathbf{2}} \mathbf{V s}\right)$ \\
\hline O Room & -3.96 & $1.39 \times 10^{4}$ & 314 & 8.19 \\
Tundra & -3.81 & $1.94 \times 10^{4}$ & 221 & 8.34 \\
Antarctic & -3.74 & $1.73 \times 10^{4}$ & 246 & 7.29 \\
Taiga & -3.80 & $1.88 \times 10^{4}$ & 221 & 7.72 \\
Greenlands & -3.86 & $6.73 \times 10^{3}$ & 604 & 8.22 \\
Rainforest & -3.95 & $2.13 \times 10^{4}$ & 270 & 8.49 \\
Jungle & -4.02 & $1.38 \times 10^{3}$ & 588 & 8.58 \\
Savannah & -3.94 & $2.17 \times 10^{4}$ & 257 & 8.72 \\
Desert & -3.86 & $2.19 \times 10^{4}$ & 270 & 9.01
\end{tabular}

\section{RESULTS AND DISCUSSION}

\subsection{Climate Zones}

The TFT response to weather variations was evaluated by reproducing the most extreme climes on Earth planet, with their typical temperatures and relative humidity conditions as shown in Figure 2A. The transfer characteristics and the corresponding output were grouped for temperature below and above room $\mathrm{T}$, in Figures $\mathbf{2 B}, \mathbf{C}$, respectively. For each weather condition, the transfer characteristic was acquired in the linear region $\left(\mathrm{V}_{D S}=0.1 \mathrm{~V}\right)$ and saturation region $\left(\mathrm{V}_{D S}=3 \mathrm{~V}\right)$. The gate current was not affected by climatic variations and 
A

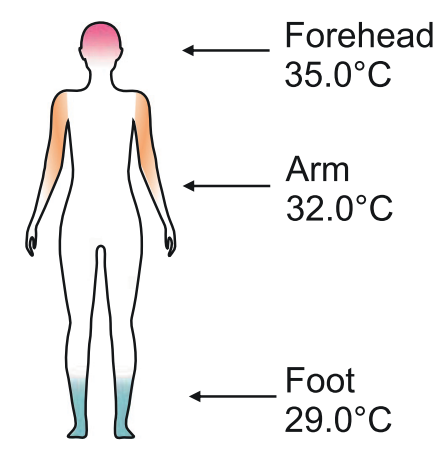

C

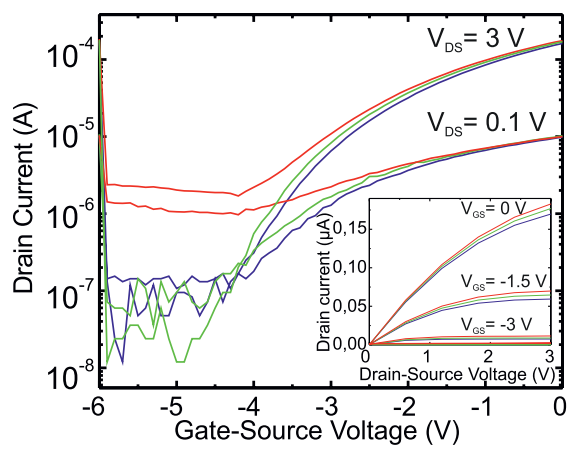

B

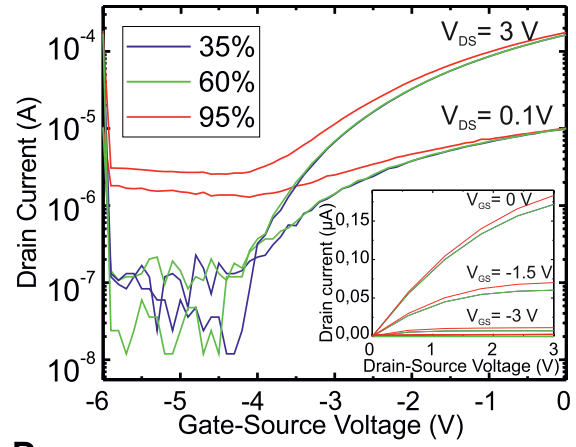

D

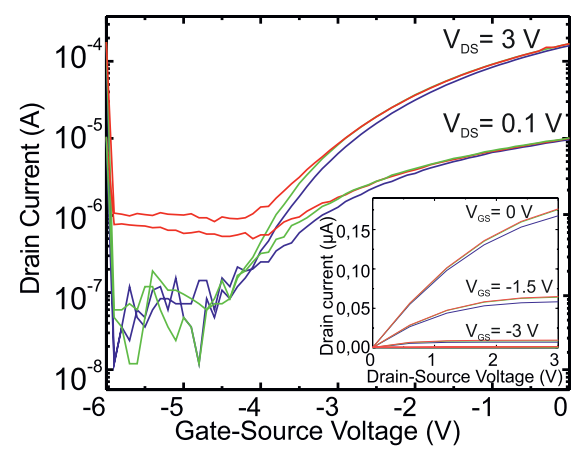

FIGURE 3 | IGZO TFTs performance for on-skin applications. (A) Simulated body locations. Transfer characteristics and corresponding output (insets) for (B) forehead, (C) arm, and (D) foot at three different RH levels: normal (60\%), low (35\%), high (95\%). W/L equals to $560 \mu \mathrm{m} / 60 \mu \mathrm{m}$.

remained constant in the microampere $(\mu \mathrm{A})$ range. The electrical performance parameters are shown in Table $\mathbf{1}$ according to the order of the experiment. First, the TFT performances were evaluated from room $\mathrm{T}$ and $\mathrm{RH}\left(23.7^{\circ} \mathrm{C}, 55 \%\right)$ to negative temperatures. In particular, different climate conditions were simulated in the following order: Tundra $\left(-2.0^{\circ} \mathrm{C}, 0 \%\right)$, Antarctic $\left(-30.0^{\circ} \mathrm{C}, 0 \%\right)$, Taiga $\left(-13.0^{\circ} \mathrm{C}, 0 \%\right)$, Greenlands $\left(8.0^{\circ} \mathrm{C}, 60 \%\right)$, Rainforest $\left(15.0^{\circ} \mathrm{C}, 80 \%\right)$. This protocol has allowed stable conditions (temperature and humidity) in the climate chamber during the TFT characterization. Within this region, a first positive shift of $0.22 \mathrm{~V}$ was observed from the initial condition to $-30.0^{\circ} \mathrm{C}, 0 \%$ while the other parameters remained stable. Then, $\mathrm{T}$ was progressively increased up to $15.0^{\circ} \mathrm{C}$ as well as the $\mathrm{RH}$ from $0 \%$ to $80 \%$. Here, an opposite shift of $\mathrm{V}_{T H}$ was observed to a more negative value. This trend of $\mathrm{V}_{T H}$ was in agreement with literature results showing how water vapour absorption induced charges accumulation on the active layer by depleting the channel Kim et al. (2017), Park et al. (2008). Coherently, the gradual reduction of $\mathrm{V}_{T H}$ was observed up to Jungle conditions $\left(26.0^{\circ} \mathrm{C}, 90 \%\right)$. Finally, a major impact of $\mathrm{RH}$ was observed when the device was brought to the high temperature zones with a reduction of RH. Specifically, the following geographical locations were mimicked: Savannah $\left(29.0^{\circ} \mathrm{C}, 60 \%\right)$, and Desert $\left(50.0^{\circ} \mathrm{C}, 22 \%\right)$. Despite $\mathrm{T}$ increasing up to $50.0^{\circ} \mathrm{C}$ between these two locations, the overall effect on $\mathrm{V}_{T H}$ was a positive shift from $-4.02 \mathrm{~V}$ to $-3.86 \mathrm{~V}$. An increase of the $\mathrm{I}_{\text {off }}$ was denoted at high variations of the $\mathrm{RH}(\Delta \mathrm{RH}>30 \%)$, in agreement with Park et al. (2008). Accordingly, the $\mathrm{I}_{\text {on }} / \mathrm{I}_{\text {off }}$ ratio reduced of one order of magnitude down to $6.73 \times 10^{3}$ and the SS deteriorated. Differently from the other parameters, the linear mobility was not influenced by RH since it increased with $\mathrm{T}$, showing a maximum variation of $10 \%$ at the highest $\mathrm{T}\left(50.0^{\circ} \mathrm{C}\right.$, Desert).

\subsection{On-Skin Applications}

The TFT suitability for wearable applications and epidermal electronics was evaluated by testing the device at three $\mathrm{RH}$ (low 35\%, normal 60\%, high 95\%) and three temperatures to resemble the different body locations, as highlighted in Figure 3A. In particular, the transfer characteristics and the corresponding output are shown in Figure 3B for the forehead at $35.0^{\circ} \mathrm{C}$, in Figure $3 \mathrm{C}$ for the arm at $32.0^{\circ} \mathrm{C}$, and in Figure $3 \mathrm{D}$ for the foot at $29.0^{\circ} \mathrm{C}$. The performance parameters are shown in Table 2. The $\mathrm{V}_{T H}$ dependence from both $\mathrm{T}$ and $\mathrm{RH}$ was coherent with expectations. The smallest value for $\mathrm{V}_{T H}(-4.12 \mathrm{~V})$ was measured in the forehead at $35.0^{\circ} \mathrm{C}, 95 \%$ by proving the impact of increasing both $\mathrm{T}$ and $\mathrm{RH}$ on this parameter. On the other hand, the positive shift of the $\mathrm{V}_{T H}$ was observed according to the increase of $\mathrm{RH}$, while keeping $\mathrm{T}$ constant Chowdhury et al. (2015). A clear influence on the TFT performance was observed at high humidity. Here, the $\mathrm{I}_{\text {off }}$ was dramatically increased, deteriorating the $\mathrm{I}_{\text {on }} / \mathrm{I}_{\text {off }}$ ratio by two orders of magnitude. Furthermore, the SS increased to $1.5 \mathrm{~V} / \mathrm{dec}$ at the hottest $\mathrm{T}$ and $95 \%$ meaning a less efficient TFT switching operation. 
TABLE 2 | TFT electrical performance parameters at different body locations.

\begin{tabular}{|c|c|c|c|c|c|}
\hline $\boldsymbol{R H}$ & Body T & $V_{T H}(\mathrm{~V})$ & $I_{\text {on }} / I_{\text {off }}$ & SS (mV/dec) & $\mu_{\text {lin }}\left(\mathrm{cm}^{2} / \mathrm{Vs}\right)$ \\
\hline \multirow[t]{3}{*}{$95 \%$} & foot, $29.0^{\circ} \mathrm{C}$ & -3.99 & $2.87 \times 10^{2}$ & 1004 & 8.48 \\
\hline & arm, $32.0^{\circ} \mathrm{C}$ & -4.12 & $1.58 \times 10^{2}$ & 1272 & 8.50 \\
\hline & forehead, $35.0^{\circ} \mathrm{C}$ & -4.15 & $1.09 \times 10^{2}$ & 1428 & 8.32 \\
\hline \multirow[t]{3}{*}{$60 \%$} & foot, $29.0^{\circ} \mathrm{C}$ & -3.86 & $2.15 \times 10^{4}$ & 200 & 8.72 \\
\hline & arm, $32.0^{\circ} \mathrm{C}$ & -3.95 & $2.19 \times 10^{4}$ & 419 & 8.77 \\
\hline & forehead, $35.0^{\circ} \mathrm{C}$ & -3.94 & $2.17 \times 10^{4}$ & 257 & 9.35 \\
\hline \multirow[t]{3}{*}{$35 \%$} & foot, $29.0^{\circ} \mathrm{C}$ & -3.85 & $2.11 \times 10^{4}$ & 332 & 8.62 \\
\hline & arm, $32.0^{\circ} \mathrm{C}$ & -3.85 & $2.13 \times 10^{4}$ & 286 & 8.78 \\
\hline & forehead, $35.0^{\circ} \mathrm{C}$ & -3.84 & $2.15 \times 10^{4}$ & 176 & 9.22 \\
\hline
\end{tabular}

Regarding the mobility variation, the results showed its dependence on both $\mathrm{T}$ and $\mathrm{RH}$. A reduction of the linear mobility was observed when the $\mathrm{RH}$ changed from the normal condition (60\%) to both high and low levels. This was coherent to previous experiments performed at constant $\mathrm{T}$ reporting the electronics characterization of two a-IGZO TFTs stored at ultra-dry condition (5\%) and high humidity (95\%) Lee and Jeong (2018).

After all the experiments, the TFT was again characterized at room $\mathrm{T}$ and $\mathrm{RH}\left(26.0^{\circ} \mathrm{C}, 55 \%\right)$. The results showed a variation of $\mathrm{V}_{T H}$ of $0.2 \mathrm{~V}\left(\mathrm{~V}_{T H}=-3.76 \mathrm{~V}\right)$, stable $\mathrm{I}_{\text {on }} / \mathrm{I}_{\text {off }}$ ratio $\left(\mathrm{I}_{\text {on }} / \mathrm{I}_{\text {off }}=2.04 \times 10^{4}\right)$ and an increase of the $\mu_{\text {lin }}$ less than $5 \%\left(\mu_{\text {lin }}=8.37 \mathrm{~cm}^{2} / \mathrm{Vs}\right)$ compared to the starting values $\left(V_{T H}=-3.96 \mathrm{~V}, I_{\text {on }} / I_{\text {off }}=1.39 \times 10^{4}\right.$, $\left.\mu_{\text {lin }}=8.10 \mathrm{~cm}^{2} / \mathrm{Vs}\right)$. The stability of the IGZO TFT to T and $\mathrm{RH}$ conditions is linked with the presence of the $\mathrm{Al}_{2} \mathrm{O}_{3}$ passivation layer, preventing the device degradation due to moisture absorption Corsino et al. (2020), and oxygen vacancies formations Zhou et al. (2014).

\section{CONCLUSION}

In this work, the suitability of a-IGZO TFT as active electronics and sensor monitoring device was proved. The electronics parameters coherently changed under extreme $\mathrm{T}$ and $\mathrm{RH}$ variations while TFT operation was preserved. Evaluating the TFT performance at the corresponding $\mathrm{T}$ and $\mathrm{RH}$ conditions of several simulated geographical locations as well as human body parts, $\mathrm{V}_{T H}$ has undergone a positive/negative shift according to the reduction/increase of both $\mathrm{T}$ and $\mathrm{RH}$. A greater influence on switching operation was also observed at $\mathrm{RH}>90 \%$. The sensitivity to epidermal microclimate defined the a-IGZO TFTs as an appropriate

\section{REFERENCES}

Billah, M. M., Hasan, M. M., and Jang, J. (2017). Effect of Tensile and Compressive Bending Stress on Electrical Performance of Flexible A-IGZO TFTs. IEEE Electron. Device Lett. 38, 890-893. doi:10.1109/ LED.2017.2707279

Cherenack, K., Zysset, C., Kinkeldei, T., Münzenrieder, N., and Tröster, G. (2010). Woven Electronic Fibers with Sensing and Display Functions for Smart Textiles. Adv. Mater. 22, 5178-5182. doi:10.1002/adma.201002159 candidate for health monitoring sensors. Future works have to consider the combined effect of $\mathrm{T}$ and $\mathrm{RH}$ with other triggering effects, such as illumination and/or mechanical stress, to support the functionality of the device as a part of a wearable integrated electronic system working at any environmental condition.

\section{DATA AVAILABILITY STATEMENT}

The raw data supporting the conclusions of this article will be made available by the authors, without undue reservation.

\section{AUTHOR CONTRIBUTIONS}

FC conceived the work and wrote the article. FC, HSO, MCA, and MC carried out the experiments. MCA customized the labVIEW program. SP, NM, and GC supervised the work.

\section{FUNDING}

This work was partially supported by the Free University of Bozen (RTD Call FAST 2020, FERMI), by the Autonomous Province of Bozen-Bolzano/South Tyrol (Provincia Autonoma di Bolzano/ Alto Adige-Ripartizione Innovazione, Ricerca, Universitá e Musei) through the International Joint Cooperation between South Tyrol-Switzerland (FLEXIBOTS, grant no.: 2/34), by the Autonomous Province of Bolzano-South Tyrol's European Regional Development Fund (ERDF) Program (project codes EFRE/FESR 1068-Senslab), and by the Open Access Publishing Fund of the Free University of Bozen-Bolzano.

Choi, J.-H., and Loftness, V. (2012). Investigation of Human Body Skin Temperatures as a Bio-Signal to Indicate Overall thermal Sensations. Building Environ. 58, 258-269. doi:10.1016/j.buildenv.2012.07.003

Chowdhury, M. D. H., Mativenga, M., Jae Gwang Um, J. G., Mruthyunjaya, R. K., Heiler, G. N., Tredwell, T. J., et al. (2015). Effect of $\mathrm{SiO} 2$ and $\mathrm{SiO} 2 / \mathrm{SiNx}$ Passivation on the Stability of Amorphous Indium-Gallium Zinc-Oxide ThinFilm Transistors under High Humidity. IEEE Trans. Electron. Devices 62, 869-874. doi:10.1109/TED.2015.2392763

Corsino, D. C., Bermundo, J. P. S., Fujii, M. N., Takahashi, K., Ishikawa, Y., and Uraoka, Y. (2020). Bias Stress and Humidity Exposure of Amorphous InGaZnO 
Thin-Film Transistors with Atomic Layer Deposited Al2O3 Passivation Using Dimethylaluminum Hydride at $200{ }^{\circ}$ C. J. Phys. D: Appl. Phys. 53, 165103. doi:10.1088/1361-6463/ab6e97

Costa, J. C., Pouryazdan, A., Panidi, J., Spina, F., Anthopoulos, T. D., Liedke, M. O., et al. (2019). Flexible IGZO TFTs and Their Suitability for Space Applications. IEEE J. Electron. Devices Soc. 7, 1182-1190. doi:10.1109/jeds.2019.2931614

Cravello, B., and Ferri, A. (2008). Relationships between Skin Properties and Environmental Parameters. Skin Res. Technol. 14, 180-186. doi:10.1111/j.16000846.2007.00275.x

Dong, C., Xu, J., Zhou, Y., Zhang, Y., and Xie, H. (2019). Light-illumination Stability of Amorphous InGaZnO Thin Film Transistors in Oxygen and Moisture Ambience. Solid-State Elect. 153, 74-78. doi:10.1016/j.sse.2018.12.020

Gao, W., Emaminejad, S., Nyein, H. Y. Y., Challa, S., Chen, K., Peck, A., et al. (2016). Fully Integrated Wearable Sensor Arrays for Multiplexed In Situ Perspiration Analysis. Nature 529, 509-514. doi:10.1038/nature16521

Geng, D., Chen, Y. F., Mativenga, M., and Jang, J. (2017). Touch Sensor Array with Integrated Drivers and Comparator Using A-IGZO TFTs. IEEE Electron. Device Lett. 38, 391-394. doi:10.1109/LED.2017.2661405

Godo, H., Kawae, D., Yoshitomi, S., Sasaki, T., Ito, S., Ohara, H., et al. (2010). Temperature Dependence of Transistor Characteristics and Electronic Structure for Amorphous In-Ga-Zn-Oxide Thin Film Transistor. Jpn. J. Appl. Phys. 49, 03CB04. doi:10.1143/jjap.49.03cb04

Hasan, M. M., Billah, M. M., Naik, M. N., Um, J. G., and Jang, J. (2017). Bending Stress Induced Performance Change in Plastic Oxide Thin-Film Transistor and Recovery by Annealing at $300{ }^{\circ} \mathrm{C}$. IEEE Electron. Device Lett. 38, 1035-1038. doi:10.1109/LED.2017.2718565

Hoshino, K., Yeh, B., and Wager, J. F. (2013). Impact of Humidity on the Electrical Performance of Amorphous Oxide Semiconductor Thin-Film Transistors. Jnl Soc. Info Display 21, 310-316. doi:10.1002/jsid.184

Kim, B., Chong, E., Hyung Kim, D., Woo Jeon, Y., Hwan Kim, D., and Yeol Lee, S. (2011). Origin of Threshold Voltage Shift by Interfacial Trap Density in Amorphous InGaZnO Thin Film Transistor under Temperature Induced Stress. Appl. Phys. Lett.Phys. Lett. 99, 062108. doi:10.1063/1.3615304

Kim, K. S., Ahn, C. H., Kang, W. J., Cho, S. W., Jung, S. H., Yoon, D. H., et al. (2017). An All Oxide-Based Imperceptible Thin-Film Transistor with Humidity Sensing Properties. Materials 10, 530. doi:10.3390/ma10050530

Knobelspies, S., Bierer, B., Daus, A., Takabayashi, A., Salvatore, G., Cantarella, G., et al. (2018). Photo-Induced Room-Temperature Gas Sensing with A-IGZO Based Thin-Film Transistors Fabricated on Flexible Plastic Foil. Sensors 18, 358. doi: $10.3390 / \mathrm{s} 18020358$

Lee, S.-U., and Jeong, J. (2019). Electrical Stability of Solution-Processed A-IGZO TFTs Exposed to High-Humidity Ambient for Long Periods. IEEE J. Electron. Devices Soc. 7, 26-32. doi:10.1109/JEDS.2018.2875755

Mativenga, M., Haque, F., Billah, M. M., and Um, J. G. (2021). Origin of Light Instability in Amorphous IGZO Thin-Film Transistors and its Suppression. Sci. Rep. 11, 1-12. doi:10.1038/s41598-021-94078-8

Munzenrieder, N., Cherenack, K. H., and Troster, G. (2011). The Effects of Mechanical Bending and Illumination on the Performance of Flexible IGZO TFTs. IEEE Trans. Electron. Devices 58, 2041-2048. doi:10.1109/TED.2011.2143416
Munzenrieder, N., Petti, L., Zysset, C., Gork, D., Buthe, L., Salvatore, G. A., et al. (2013). "Investigation of Gate Material Ductility Enables Flexible A-IGZO TFTs Bendable to a Radius of $1.7 \mathrm{Mm}$," in 2013 Proceedings of the European SolidState Device Research Conference (ESSDERC) (IEEE), 362-365. doi:10.1109/ ESSDERC.2013.6818893

Nomura, K., Ohta, H., Takagi, A., Kamiya, T., Hirano, M., and Hosono, H. (2004). Room-temperature Fabrication of Transparent Flexible Thin-Film Transistors Using Amorphous Oxide Semiconductors. Nature 432, 488-492. doi:10.1038/ nature 03090

Park, J.-S., Jeong, J. K., Chung, H.-J., Mo, Y.-G., and Kim, H. D. (2008). Electronic Transport Properties of Amorphous Indium-Gallium-Zinc Oxide Semiconductor upon Exposure to Water. Appl. Phys. Lett. 92, 072104. doi:10.1063/1.2838380

Park, J.-S., Kim, T.-W., Stryakhilev, D., Lee, J.-S., An, S.-G., Pyo, Y.-S., et al. (2009). Flexible Full Color Organic Light-Emitting Diode Display on Polyimide Plastic Substrate Driven by Amorphous Indium Gallium Zinc Oxide Thin-Film Transistors. Appl. Phys. Lett. 95, 013503. doi:10.1063/ 1.3159832

Salvatore, G. A., Münzenrieder, N., Kinkeldei, T., Petti, L., Zysset, C., Strebel, I., et al. (2014). Wafer-scale Design of Lightweight and Transparent Electronics that Wraps Around Hairs. Nat. Commun. 5, 1-8. doi:10.1038/ncomms3982

Sze, S. M., and Ng, K. K. (2006). Physics of Semiconductor Devices. Chichester, England, UK: Wiley.

Yabuta, H., Sano, M., Abe, K., Aiba, T., Den, T., Kumomi, H., et al. (2006). Highmobility Thin-Film Transistor with Amorphous InGaZnO4 Channel Fabricated by Room Temperature Rf-Magnetron Sputtering. Appl. Phys. Lett. 89, 112123. doi:10.1063/1.2353811

Zhou, D., Hu, Z., Wu, Q., Xu, L., Xie, H., and Dong, C. (2014). Light Illumination Stability of Amorphous InGaZnO Thin Film Transistors with Sputtered AlOxpassivation in Various Thicknesses. Jpn. J. Appl. Phys. 53, 121103. doi:10.7567/jjap.53.121103

Conflict of Interest: The authors declare that the research was conducted in the absence of any commercial or financial relationships that could be construed as a potential conflict of interest.

Publisher's Note: All claims expressed in this article are solely those of the authors and do not necessarily represent those of their affiliated organizations, or those of the publisher, the editors and the reviewers. Any product that may be evaluated in this article, or claim that may be made by its manufacturer, is not guaranteed or endorsed by the publisher.

Copyright (๑) 2022 Catania, Oliveira, Costa Angeli, Ciocca, Pané, Münzenrieder and Cantarella. This is an open-access article distributed under the terms of the Creative Commons Attribution License (CC BY). The use, distribution or reproduction in other forums is permitted, provided the original author(s) and the copyright owner(s) are credited and that the original publication in this journal is cited, in accordance with accepted academic practice. No use, distribution or reproduction is permitted which does not comply with these terms. 